\title{
Macrolepiota procera (Scop.) Singer. Mantarının Ağır Metal İçeriklerinin ve Oksidatif Stres Durumunun Belirlenmesi
}

\author{
Hasan AKGÜL1ㄴ, Mustafa SEVINDIIK ${ }^{*}$, Ilgaz AKATA², Deniz ALTUNTAŞ ${ }^{3}$ Celal BAL ${ }^{4}$, Muhittin DoĞAN \\ ${ }^{1}$ Akdeniz Üniversitesi, Fen Fakültesi, Biyoloji Bölümü, 07058, Antalya \\ ${ }^{2}$ Ankara Üniversitesi, Fen Fakültesi, Biyoloji Bölümü, 06100, Ankara \\ ${ }^{3}$ Muğla Sıtkı Koçman Üniversitesi, Fen Fakültesi, Biyoloji Bölümü, 48000, Muğla \\ ${ }^{4}$ Gaziantep Üniversitesi, Oğuzeli MYO, 27900, Gaziantep \\ ${ }^{5}$ Gaziantep Üniversitesi, Fen-Edebiyat Fakültesi, Biyoloji Bölümü, 27310, Gaziantep
}

(Alınış / Received: 01.05.2016, Kabul / Accepted: 06.06.2016, Online Yayınlanma / Published Online: 16.06.2016)

\section{Anahtar Kelimeler \\ Macrolepiota procera, Şemsiye mantarı, Antioksidan, Oksidan, Ağır metal}

\begin{abstract}
Özet: İnsanlar yüzyıllardır mantarları doğrudan doğal ortamlarından elde etme yoluna gitmiş ve farklı amaçlarla kullanmıştır. İnsanların doğadan temin ettikleri mantarların faydalarının ve zararlarının tespiti insan sağlığı açısından önemlidir. $\mathrm{Bu}$ nedenle bu çalışmada, halk arasında şemsiye mantarı olarak bilinen ve yaygın olarak tüketilen Macrolepiota procera (Scop.) Singer mantarının Balıkesir (Kazdağı Milli Parkı) ve Antalya (Akseki) illerinden toplanan örneklerinin TAS (Toplam Antioksidan Seviyesi), TOS (Toplam Oksidan Seviyesi) seviyeleri ile mantar ve toprak örneklerinin ağır metal içeriklerinin belirlenmesi ve kıyaslanması amaçlanmaktadır. Yapılan çalışmalar sonucunda Akseki'den toplanan mantar örneklerinde OSİ (TOS/TASx10) değerinin 0.367, Kazdağı'ndan toplanan örneklerde ise 0.235 olarak belirlenmiştir. Ağır metal seviyelerinin Akseki'den toplanan örneklerde daha fazla olduğu tespit edilmiştir. Kazdağı Milli Parkından toplanan örneklerin daha sağlıklı olduğu görülmektedir. Ayrıca Kazdağı'nda mantarların yetişmesi için daha az oksidatif stresin olduğu ve buna bağlı olarak daha uygun bir ortam olduğu söylenebilir.
\end{abstract}

\section{Determination of Heavy Metal Content and Oxidative Stress Status of Macrolepiota procera (Scop.) Singer. Mushroom}

\author{
Keywords \\ Macrolepiota procera, \\ Parasol mushroom, \\ Antioxidant, \\ Oxidant, \\ Heavy metal
}

\begin{abstract}
For centuries, people have sought to obtain mushrooms directly from the natural environment and used for different purposes. People has been examining the pros and the cons of consuming mushrooms for human health. For instance, Macrolepiota procera (Scop.) Singer, also known as parasol mushrooms, which are widely consumed. Here, we have opted these mushrooms as samples to compare and contrast the status and, the heavy metal content in TAS (Total Antioxidant Status) and, TOS (Total Oxidant Status ). These mushroom samples and soil samples are collected from Balıkesir (Kazdağı National Park) and Antalya (Akseki) provinces. As a result of our findings, OSİ of fungal samples 0.367 collected from Akseki, while is determined to be 0.235 in samples collected from Kazdagi. Heavy metal levels has been found to be more in samples collected from Akseki. In contrast to the samples collected from the Kazdağ National Park, it is considered to be more healthy. Also to be less oxidative stress for the growth of fungi and said that consequently a more appropriate environment in Kazdaği.
\end{abstract}

\section{Giriş}

İnsanlar yüzyıllardır mantarları doğadan doğrudan temin etme yoluna gitmiş ve farklı amaçlarla kullanmışlardır. Mantarların son yıllarda özellikle yüksek, besin elementleri, protein ve vitamin içerikleri gibi yüksek besin değerleri ve lezzetlerinden dolayı dünya genelinde popüler gıda olmaya adaylardır [1].

Besin değerlerinin yanı sıra mantarlar, doğada organik madde yıkımında rol aldıklarından kullandıkları substrat içeriğine bağlı olarak 
bünyelerinde ve bulunduğu ortamda element içeriğinde değişime neden olurlar [2]. Bu sebeple mantarların ağır metal konsantrasyonları tarımsal kültür bitkileri, meyve ve sebzelere kıyasla çok daha yüksektir [3]. Canlılar için demir (Fe), kobalt (Co), bakır $(\mathrm{Cu})$, mangan $(\mathrm{Mn})$, krom $(\mathrm{Cr})$ ve çinko $(\mathrm{Zn})$ gibi ağır metallerin eser miktarda gerekli olmasına karşılık, arsenik (As), kadmiyum (Cd) ve kurşun (Pb) gibi ağır metaller zararlı olarak kabul edilmektedir [3].

Çevre kirliliği gibi bazı durumlarda oluşan oksidatif stres [4], sonucunda insanlarda kalp hastalıkları, nörolojik hastalıklar, diyabet ve lösemi de dahil olmak üzere birçok sağlık sorunu ortaya çıkabilir [5]. Oksidatif stresin etkisini azaltmak için vücutta üretilen antioksidanlar devreye girerek hücrelerin zarar görmesini engeller [4]. Fakat oksidatif stresin yüksek olması sonucunda dışarıdan antioksidanlarca zengin gıdaların tüketilmesi gerekmektedir[6]. Bu kapsamda gıda olarak tüketilen mantarların ağır metal içerikleri, antioksidan, oksidan ve oksidatif stres seviyelerinin belirlenmesi insan sağlığı açısından önem arz etmektedir.

$\mathrm{Bu}$ çalışmada halk arasında şemsiye mantarı olarak bilinen ve yaygın olarak tüketilen Macrolepiota procera (Scop.) Singer mantarının Balıkesir (Kazdağı Milli Parkı) ve Antalya (Akseki) illerinden toplanan örneklerinin TAS (Toplam Antioksidan Seviyesi), TOS (Toplam Oksidan Seviyesi), OSİ (Oksidatif Stres İndeksi) değerleri ile mantar ve toprak örneklerinin ağır metal içeriklerinin belirlenmesi ve kıyaslanması amaçlanmıştır.

\section{Materyal ve Metot}

Çalışmada kullanılan Macrolepiota procera (Scop.) Singer (1) doğal örnekleri Balıkesir (Kaz Dağı Milli Parkı) ve Antalya (Akseki) illerinden toplanmıştır. Laboratuvar ortamina getirilen mantar örnekleri $40^{\circ} \mathrm{C}$ 'de inkübatörde kurutulmuştur. Kurutma işleminden sonra mekanik öğütücü yardımı ile toz haline getirilmiştir. Daha sonra ögütülen mantarlar 30'ar g tartılarak kartuşlanıp soxhlet ekstraktöründe yaklaşık olarak 6 saat süreyle $75{ }^{\circ} C^{\prime}$ de etanol ile özütleri çıkartılmıştır (BUCHI Extraction System Model B-811).

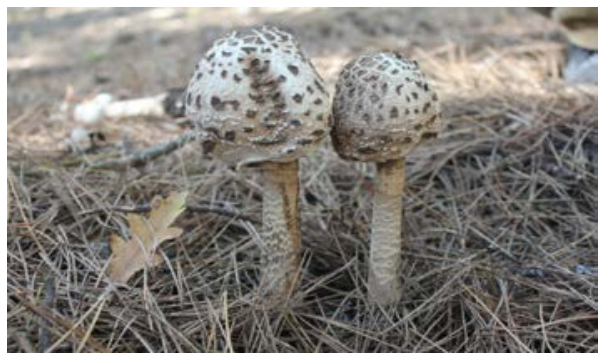

Şekil 1. Macrolepiota procera (Scop.) Singer (1) Elde edilen özütler daha sonra basınç altında rotary evaporatörle $40{ }^{\circ} \mathrm{C}^{\prime}$ de yoğunlaştırılıp, $+4{ }^{\circ} \mathrm{C}^{\prime}$ de deney yapılacak hale getirilmiştir. (BUCHI Rotavapor Model R-144).

\subsection{TAS, TOS ve OSİ değerlerinin belirlenmesi}

Mantarların toplam antioksidan seviyeleri (TAS) ve oksidan seviyeleri (TOS), Rel Assay marka ticari kitler (Rel Assay Kit Diagnostics, Türkiye) kullanılarak ölçülmüştür. TAS testleri için kalibratör olarak E vitamininin suda çözünür bir analoğu olan Trolox kullanılmıştır. Sonuçlar mmol Trolox equiv./L olarak ifade edilmiștir[7]. TOS testleri için kalibratör olarak hidrojen peroksid kullanılmıştır. Sonuçlar $\mu$ mol $\mathrm{H}_{2} \mathrm{O}_{2}$ equiv./L olarak ifade edilmiştir. [8]. TOS düzeylerinin TAS düzeylerine oranının yüzde derecesi olarak ifade edilen OSİ hesaplanırken, TAS testinin birimindeki mmol değeri TOS testindeki gibi $\mu$ mol birimine çevrilmiştir [8]. Sonuçlar aşağıdaki formüle göre hesaplanmıştır.

OSI $=$

TOS, $\mu \mathrm{mol} \mathrm{H}_{2} \mathrm{O}_{2}$ equiv./L

TAS, mmol Trolox equiv./L X 10

\subsection{Ağır metal içeriklerinin belirlenmesi}

Mantar örnekleri etüvde $80^{\circ} \mathrm{C}$ 'de sabit tartıma kadar kurutulduktan sonra havanda öğütülmüștür. Bu örneklerden 3 tekerrür şeklinde 1'er gram tartılmış ve 50 mL'lik cam erlenlere konulmuştur. Üzerine 10 mL konsantre $\mathrm{HNO}_{3}$ eklenmiş ve oda sıcaklığında 24 saat bekletilmiştir. Örnekler ısıtıcı tabla üzerinde tortu kalıncaya kadar isıtılmıştır. Daha sonra bu erlenlerin üzerine $10 \mathrm{~mL}$ konsantre HCI eklenmiş yakma ișlemi yenilenmiştir. Yakma ișlemini takiben örnekler üzerine $20 \mathrm{~mL}$ seyreltik $\mathrm{HCl}$ eklenerek tamamlanmış ve analiz için hazır hale getirilmiştir [9].

Mantar örneklerinin toplandığı alandan alınan toprak örnekleri mantarın bulundukları noktadan dikey olarak 15-20 cm derinliğinde açlan çukurun kesit yüzeyinden alınarak karıştırılmıştır. Mantarların örnekleme zamanında alınan toprak örnekleri laboratuvarda tozlardan ve kimyasal etkilerden uzak bölgelerde kurumaya bırakılmış ve daha sonra tartılarak darası bilinen cam petri kaplarda $105^{\circ} \mathrm{C}^{\prime}$ ye ayarlı etüvde 48 saat bekletilerek kurutulmuştur. Kurutulan toprak örnekleri, porselen havanda toz haline getirilmiş ve $100 \mu \mathrm{m}$ 'lik elek ile elenmiştir. [10]. Toprak örnekleri eleme işlemi yapıldıktan sonra 3 tekerrür olarak 1'er gram tartılıp erlen kaplara konulmuştur. Hazırlanan erlenlerin üzerine $10 \mathrm{~mL} \mathrm{HNO}_{3}$ eklenmiştir ve oda sıcaklığında 24 ile 48 saat arası bekletilmiștir. Erlenler daha sonra ısısı ayarlanabilen ısıtıcı üzerinde önce düşük ısıda ve sonra ısı arttırılarak çözelti berraklaşıncaya kadar ısıtılmıştır. Isıtılan örneklerin üzerine $15 \mathrm{~mL}$ seyreltik HCI eklenmiş ve süzme işlemi yapılarak falcon tüplere konulmuştur. En son aşamada çözelti $20 \mathrm{~mL}$ seyreltik HCI eklenerek tamamlanmış ve analiz için 
hazır hale getirilmiştir[9]. Mantar örneklerinin element içerikleri Perkin Elmer (AAnalyst 400) cihazı kullanılarak belirlenmiştir.

\section{Bulgular}

\subsection{TAS, TOS ve OSİ bulguları}

Farklı bölgelerden toplanan mantarın örneklerinin TAS $(\mathrm{mmol} / \mathrm{L})$, TOS $(\mu \mathrm{mol} / \mathrm{L})$ ve OSİ değerleri Tablo 1 'de verilmiștir.

Tablo 1. Mantar örneklerinin TAS, TOS ve OSİ Değerleri

\begin{tabular}{|l|l|l|l|}
\hline Lokalite & TAS & TOS & OSİ \\
\hline Akseki & 2.823 & 10.349 & 0.367 \\
\hline $\begin{array}{l}\text { Kazdağı Milli } \\
\text { Parkı }\end{array}$ & 2.805 & 6.596 & 0.235 \\
\hline
\end{tabular}

\subsection{Ağır metal içerikleri}

Yapılan analiz sonuçlarında mantar ve toprak örneklerinin ağır metal seviyeleri mg.kg-1 cinsinden belirlenmiștir. Mantar ve toprak örneklerinin ağır metal içerikleri Tablo 2'de Ortalama \pm Standart sapma olarak gösterilmiştir. Ayrıca Şekil 2, 3, 4, 5, 6 'da mantarların bünyesindeki elementlerin konsantrasyonları grafiklerde verilmiştir.

Tablo 2. Mantar ve toprak örneklerinin ağır metal seviyeleri

\begin{tabular}{|l|l|l|l|l|l|}
\hline Lokalite & Fe & Zn & Cu & Pb & Ni \\
\hline Akseki & 205.88 & 60.60 & 45.02 & $9.41 \pm$ & $2.87 \pm$ \\
Mantar & \pm 40.20 & \pm & \pm & 0.49 & 0.09 \\
& & 3.84 & 1.20 & & \\
\hline Akseki & 814.11 & 43.94 & 29.31 & 41.33 & 55.43 \\
Toprak & \pm 8.32 & \pm & \pm & \pm & \pm 1.19 \\
& & 1.18 & 0.89 & 1.52 & \\
\hline Kazdağı & 133.64 & 55.90 & 38.37 & $8.01 \pm$ & $0.18 \pm$ \\
$\begin{array}{l}\text { Milli Parkı } \\
\text { Mantar }\end{array}$ & \pm 15.40 & \pm & \pm & 0.80 & 0.05 \\
\hline $\begin{array}{l}\text { Kazdağı } \\
\text { Milli Parkı } \\
\text { Toprak }\end{array}$ & $782.36 \pm$ & 14.15 & 8.35 & & \\
\hline
\end{tabular}

\section{Fe içerigi mg.kg- ${ }^{-1}$}

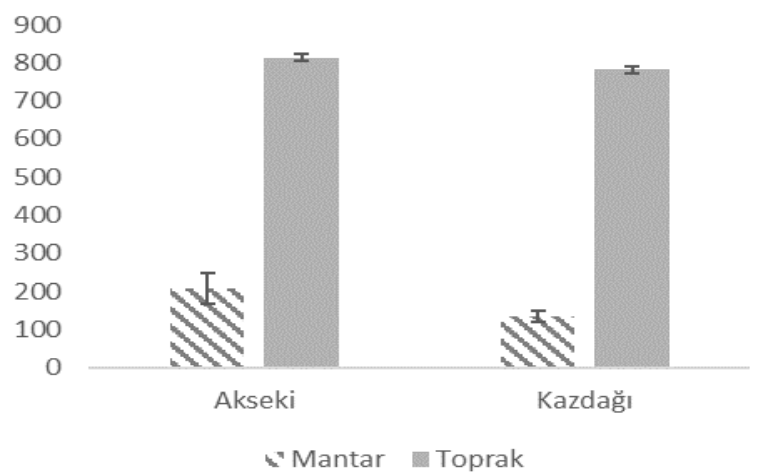

Şekil 2. Mantar ve toprak örneklerinin Fe konsantrasyonları

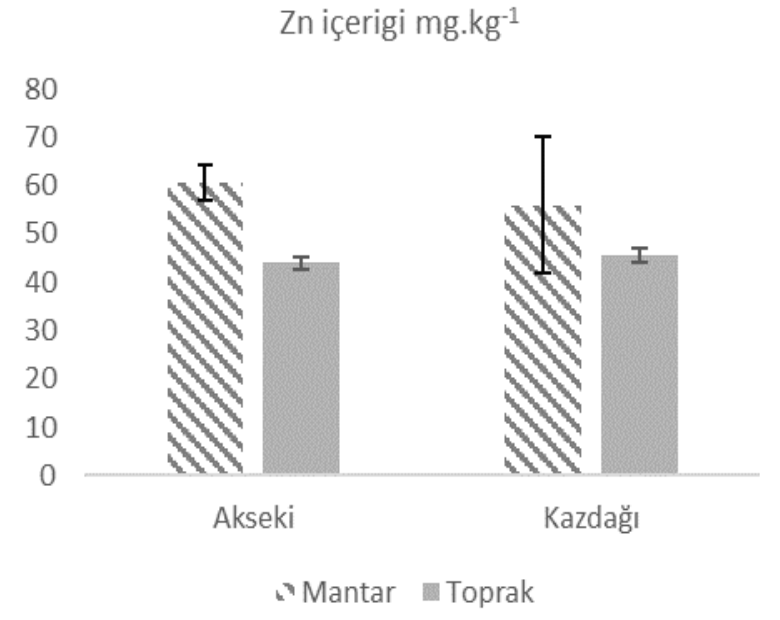

Şekil 3. Mantar ve toprak örneklerinin $\mathrm{Zn}$ konsantrasyonları

Cu içerigi mg.kg-1

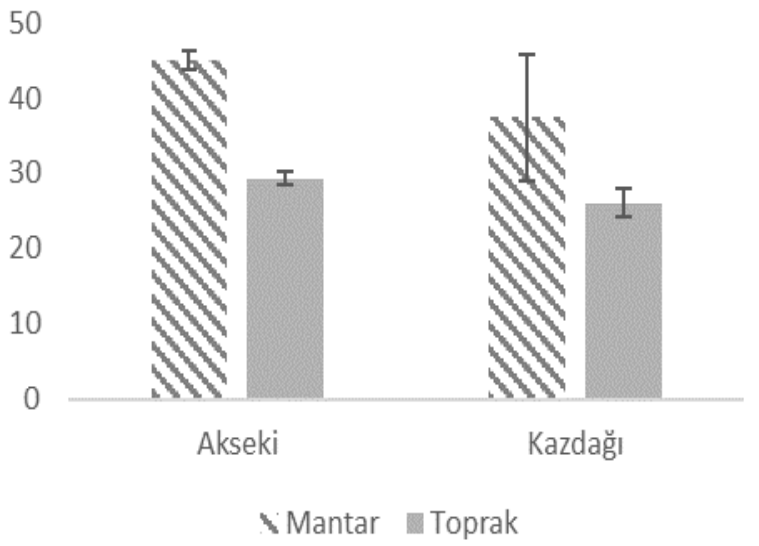

Şekil 4. Mantar ve toprak örneklerinin $\mathrm{Cu}$ konsantrasyonları

$\mathrm{Pb}$ içerigi mg. $\mathrm{kg}^{-1}$

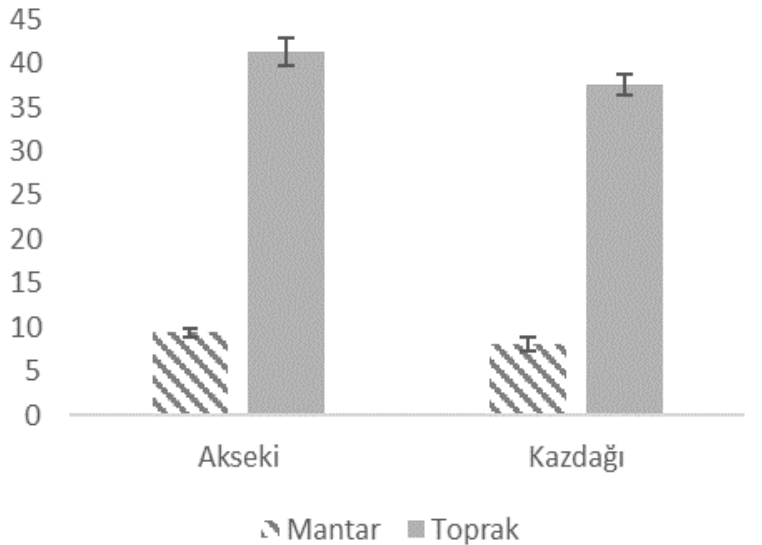

Şekil 5. Mantar ve toprak örneklerinin $\mathrm{Pb}$ konsantrasyonları 


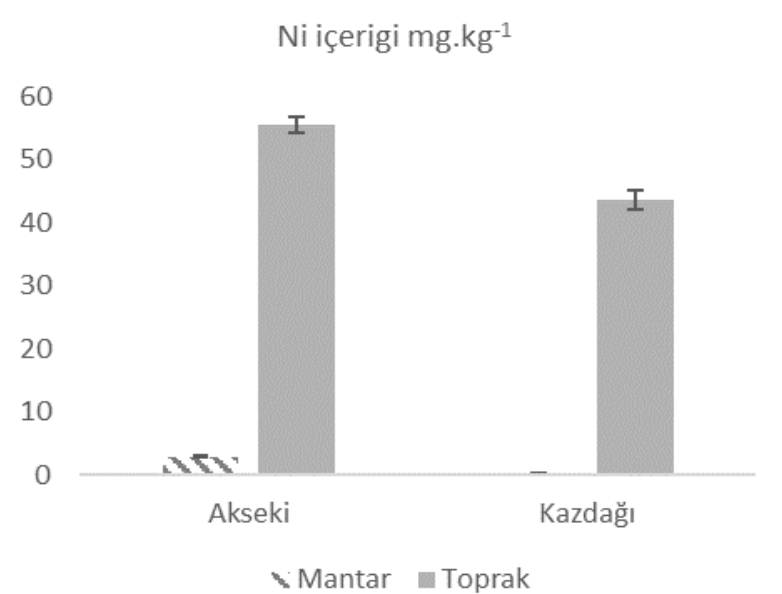

Şekil 6. Mantar ve toprak örneklerinin $\mathrm{Ni}$ konsantrasyonları

\section{Tartışma ve Sonuç}

Her iki bölgeden toplanan mantar örneklerinin toplam antioksidan değerlerinin birbirine yakın seviyelerde olduğu belirlenmiştir. Buna karşılık toplam oksidan değerleri Akseki'den toplanan örnek için Kazdağı Milli Parkından toplanan örneğe göre daha yüksek olduğu tespit edilmiştir. Oksidatif stres seviyelerinin Kazdağı Milli Parkı örnekleri için daha uygun olduğu görülmektedir.

Çoban [11], yapmış olduğu çalışmada KemaliyeErzincan'dan topladıkları yenilebilir Auricularia auricula (L. ex Hook) Underw mantarının TAS değeri 1.01, TOS değeri 23.91 olarak belirlemiștir. Bülbül [12], yapmış olduğu benzer bir çalışmada GaziantepŞahinbey'den topladıkları yenilebilir mantarlardan olan Helvella leucomelaena (Pers.) Nannf'nın TAS değerini 0.79 , TOS değerini 20.86 olarak, Sarcosphera crassa (Jacq.) J. Schröt'nın TAS değerini 0.57, TOS değerini 13.64 olarak belirlemiștir. Bu çalışmalara kıyasla her iki bölgeden toplanan mantar örneklerinin gerek toplam antioksidan gerekse toplam oksidan seviyelerinin daha iyi olduğu görülmüştür. Hem Kazdağı Milli Parkı hem de Akseki'nin Kemaliye ve Şahinbey'e göre mantarların yetişmesi için daha az oksidatif stresin olduğu ve buna bağlı olarak daha uygun bir ortam olduğu söylenebilir.

Yapılan ağır metal analizleri sonucu Akseki'den toplanan örneklerin ağır metal seviyelerinin Kazdağı Milli Parkından toplanan örneklere göre daha yüksek olduğu belirlenmiştir. Bunun yanı sıra bu iki bölgeden alınan toprak örneklerinin de $\mathrm{Zn}$ hariç diğer bütün elementler için ağır metal seviyelerinin Akseki'den toplanan örneklerde daha yüksek olduğu tespit edilmiștir. İki bölgede de ortak olarak mantarlar bünyelerinde $\mathrm{Zn}$ ve $\mathrm{Cu}$ elementlerini topraktan daha fazla bünyelerinde barındırdıkları görülmektedir. Bunun sebebinin kullandıkları substrat içeriğinden kaynaklı olduğu söylenebilir.
Mallikarjuna vd. [13], yaptıkları araştırmada mantarlar için literatürde yer alan en düşük ve en yüksek element içeriklerini belirlemiştir. Bu araştırmada belirlenen literatür değerlerine kıyasla $\mathrm{Cu}$ için her iki bölge örneklerinin daha düşük seviyelerde olduğu görülmüştür. Buna karşılık $\mathrm{Pb}$ içeriği her iki bölge içinde mantar bünyesinde literatür değerlerine göre daha yüksek olduğu görülmektedir. Sonuç olarak; Kazdağı Milli Parkından toplanan örneklerin daha sağlıklı olduğu görülmektedir. Fakat ağır metal içerikleri ve oksidan seviyeleri nedeniyle tüketiminde așırıya kaçılmaması önerilmektedir.

\section{Kaynakça}

[1] Kosanic, M., Rankovic, B., Rancic, A., Stanojkovic, T. 2016. Evaluation of metal concentration and antioxidant, antimicrobial, and anticancer potentials of two edible mushrooms Lactarius deliciosus and Macrolepiota procera. Journal of Food and Drug Analysis, (2016), 1-8.

[2] Sevindik, M., Eraslan, C.E., Akgül, H. 2015. Bazı makrofungus türlerinin ağır metal içeriklerinin belirlenmesi. Ormancılık Dergisi, 11(2), 48-53.

[3] Liu, B., Huang, Q., Cai, H., Guo, X., Wang, T., Gui, M. 2015. Study of heavy metal concentrations in wild edible mushrooms in Yunnan Province, China. Food Chemistry, 188(2015), 294-300.

[4] Sezer, K., Keskin, M. 2014. Serbest Oksijen Radikallerinin Hastalıkların Patogenezisindeki Rolü. F.Ü. Sağ. Bil. Vet. Dergisi, 28(1), 49-56.

[5] Shameem, N., Kamili, N.A., Ahmad, M., Masoodi, F.A., Parray, J.A. 2015. Radical scavenging potential and DNA damage protection of wild edible mushrooms of Kashmir Himalaya. Journal of the Saudi Society of Agricultural Sciences, (2015), 1-8. http://dx.doi.org/10.1016/j.jssas.2015.10.005

[6] Öğüt, S., Atay, E. 2012. Yaşlılık ve oksidatif stres. S.D.Ü. Tıp Fak. Dergisi. 19(2), 68-74.

[7] Erel, 0. 2004. A novel automated direct measurement method for total antioxidant capacity using a new generation, more stable ABTS radicalcation. Clin Biochem. 2004(37): 277-85.

[8] Erel, 0. 2005. A new automated colorimetric method for measuringtotal oxidant status. Clin Biochem. 2005(38): 1103-1111.

[9] Doğan, M. 2005. Ceratophyllum demersum L.'de Kadmiyum Klorür, Sodyum Klorür ve Bunların Kombinasyonlarının Fizyolojik ve Morfolojik Etkileri. Çukurova Üniversitesi Fen Bilimleri Enstitütüsü, Doktora Tezi, 137s, Adana. 
[10] Yücel, E., Doğan, F., Öztürk, M., 1995. Porsuk Çayında Ağır Metal Kirlilik Düzeyleri ve Halk Sağlığı İlişkisi. Ekoloji, 17(1995), 29-32.

[11] Çoban, C.. 2014. Auricularia auricula (L.) underw. ve Trametes versicolor (L.) LLoyd makromantar türlerinin mineral madde içeriği ve biyolojik aktivitesinin belirlenmesi. Gaziantep Üniversitesi Fen Bilimleri Enstitütüsü, Yüksek Lisans Tezi, 69s, Gaziantep.

[12] Bülbül, S.B. 2014. Gaziantep İlindeki Bazı Mikorizal Mantarlar Üzerine Biyoaktivite Araştırmaları. Gaziantep Üniversitesi Fen Bilimleri Enstitütüsü, Yüksek Lisans Tezi, 49s, Gaziantep.

[13] Mallikarjuna, S.E., Ranjini, A., Haware, D.J., Vijayalakshmi, M.R., Shashirekha, M.N., Rajarathnam, S. 2013. Mineral Composition of Four Edible Mushrooms. Journal of Chemistry (2013), 1-5. 